\title{
Carbides and Their Influence on Notched Low Cycle Fatigue Behavior of Fine- Grained IN718 Gas Turbine Disk Material
}

\author{
Prabir R. Bhowal and Agnieszka M. Wusatowska-Sarnek \\ Pratt \& Whitney Co., East Hartford, CT 06108 \\ Keywords: IN718, Low Cycle Fatigue, Carbides
}

\begin{abstract}
The notched low cycle fatigue properties of forged Inconel 718 superalloy that was heat-treated with conventional solution and aging cycles were evaluated. The microstructure of the material was fine-grained with average grain size of $8 \mu \mathrm{m}$ (ASTM 11) and with occasional grains as large as 30-40 $\mu \mathrm{m}$ (ASTM 6-7). Tests were conducted at room, intermediate $(420 \mathrm{~K}$ and $560 \mathrm{~K}$ ) and high $(810 \mathrm{~K}$ and $880 \mathrm{~K})$ temperatures at several levels of notch root 'concentrated' stress (1400$1650 \mathrm{MPa})$. The cycles to failure were analyzed in terms of stress, temperature and fatigue initiation sites. In all tests fatigue originated from either grains or carbides, and the relative occurrence of each depended on the temperature and stress of the test. At low temperature and high stress, carbide initiation was dominant, but with increased test temperature grain initiation was observed. The fatigue life reduction due to carbide initiation (relative to the grain initiation) was significant at low temperature/high stress conditions. Under these conditions, grain refinement did not improve fatigue life. These results are discussed in terms of cracking of carbides that was promoted by carbide brittleness at lower temperatures, a high 'concentrated' notch-root stress and larger carbide size.
\end{abstract}

\section{Introduction}

Inconel 718 (IN718) is a Ni-based superalloy that is widely used for rotating components in gas turbine engines. The alloy exhibits high strength and good low cycle fatigue (LCF) resistance that are critical in disk applications [1,2]. Gas turbine disks are typically produced by 'hot-die' forging of billet and grain size refinement during forging is a critical step in achieving improved LCF life of the disk $[3,4]$. It is desirable that fatigue critical disks are produced with a fine grain structure in the range 5-20 $\mu \mathrm{m}$ to maximize fatigue benefits. However, a prior study has shown that carbide initiation is promoted at high stress amplitude [5], and therefore, the carbides might limit the benefits from grain refinement under certain conditions. The purpose of the present study is thus aimed at understanding the role of carbides in notched LCF where the concentrated stress at the notch root may reach high stress levels.

\section{Material and Experimental Procedure}

Rotor grade IN718 disks were produced by commercial 'hot-die' forging practice into a contoured shape. The disk represented a forging shape for a large gas turbine engine with outer and inner (bore) diameters of $650 \mathrm{~mm}$ and $210 \mathrm{~mm}$, respectively, and a bore thickness of $97 \mathrm{~mm}$. The input stock for the forgings was a commercially available $250 \mathrm{~mm}$ diameter billet produced from double-melted (VIM+VAR) ingot. The chemistry of the billet (wt.\%) was $18.0 \% \mathrm{Cr}, 2.9 \%$ 
Mo, 1.0\% Ti, 0.48\% Al, 5.4\% Nb+Ta $(\mathrm{Ta}<0.01), 18.2 \% \mathrm{Fe}, 0.03 \% \mathrm{C}$, and balance Ni. The forging was given a conventional $1227 \mathrm{~K}$ solution treatment with oil-quench and a standard IN718 aging cycle. The combined forging and heat treatment processing was intended to yield fine-grained microstructure. The typical tensile properties of the heat-treated disk are given in Table I.

Table I. Typical tensile properties of IN718 disk forging used in present study.

\begin{tabular}{cccc}
\hline Temperature $(\mathrm{K})$ & $\sigma \mathrm{Y}(\mathrm{MPa})$ & $\sigma \mathrm{UTS}(\mathrm{MPa})$ & $\varepsilon_{\mathrm{f}}(\%)$ \\
\hline 293 & 1172 & 1434 & 18 \\
560 & 1068 & 1282 & 18 \\
810 & 1006 & 1206 & 20 \\
\hline
\end{tabular}

Low cycle fatigue (LCF) specimens were extracted from the disk forging in the hoop orientation. The specimens were flat with a rectangular gage section of nominal dimensions $38 \mathrm{~mm} \times 37 \mathrm{~mm}$ $\mathrm{x} 3.7 \mathrm{~mm}$. The notch feature was introduced by machining a central and through thickness hole producing a stress concentration $\left(\mathrm{K}_{\mathrm{t}}\right)$ of 2.5 during axial LCF loading of the specimen. Besides the effect of $\mathrm{K}_{\mathrm{t}}$, the surface condition of the hole was important in influencing the LCF life. The hole was machined by single-point boring that left machining marks parallel to the stress axis (Fig. 1a.). In addition, the surface carbides showed a 'damaged' appearance as shown in Fig. $1 \mathrm{~b}$. A limited number of LCF tests were performed with the as-machined surface condition to determine the role of these 'damaged' carbides, but a majority of tests were performed on specimens with a 'media-finished' surface. For media finishing, medium-sized-fused-cast $\mathrm{Al}_{2} \mathrm{O}_{3}$ granules were used. The media-finished surface appearance is shown in Fig. 2.
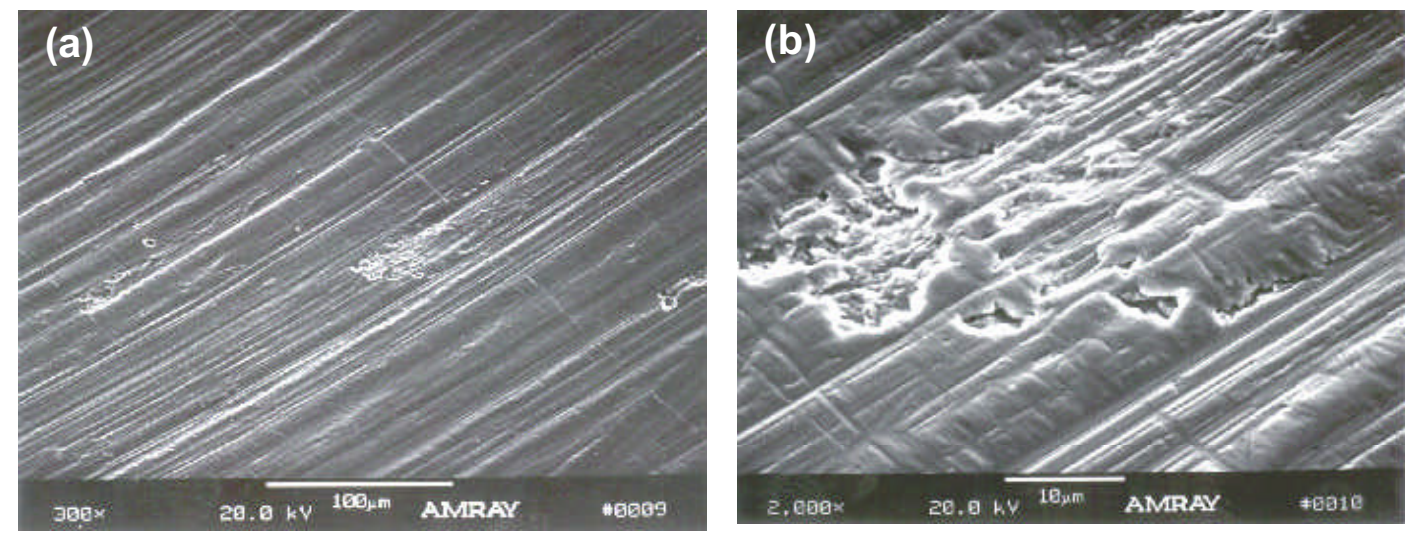

Figure 1. SEM images showing (a) as-machined notch surface (machining marks left after single-point boring), and (b) carbide appearance on as-machined notch surface.

The LCF tests were carried out in air at room, intermediate $(420 \mathrm{~K}$ and $560 \mathrm{~K})$ and high $(810 \mathrm{~K}$ and $880 \mathrm{~K}$ ) temperatures at several levels of notch root 'concentrated' stress (1400-1650 MPa). Tests were performed in a modified MTS servo-hydraulic machine using sinusoidal waveform loading using a min to max stress ratio $(\mathrm{R})$ of 0.05 , and test frequencies of $1 \mathrm{~Hz}$ and $0.5 \mathrm{~Hz}$ at low/moderate and high temperatures, respectively. Fracture surfaces and crack initiation sites of fractured specimens were studied by optical and scanning electron microscopy (SEM) equipped with energy dispersive X-ray spectroscopy (EDS). 


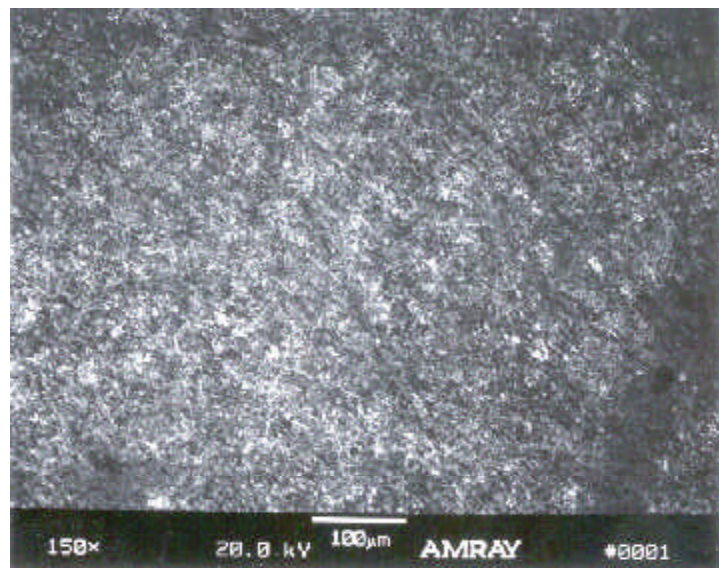

Figure 2. SEM image showing example of surface appearance of the mediafinished notch.

\section{Results and Discussion}

\section{Microstructure}

The microstructure of the forged and heat treated disk is shown in Fig. 3a. The average gamma $(\gamma)$ grain size was $8 \mu \mathrm{m}$ (ASTM 11) with grain size varying in the range ASTM 10-12 depending on the location in the disk. Occasional grains with sizes as large as 30 to $40 \mu \mathrm{m}$ (ASTM 6-7) were also observed but they represented a small area fraction $(<2 \%)$ in the microstructure. Further, the microstructure contained $\mathrm{Cr}$-rich $\mathrm{M}_{2} \mathrm{C}_{6}$ and $\mathrm{Nb}$ /Ti-rich $\mathrm{MC}$ carbides, spherodized delta-phase $\left(\delta: \mathrm{Ni}_{3} \mathrm{Nb}\right)$, and two strengthening phases: $\gamma^{\prime}$ and $\gamma^{\prime \prime}$ precipitates [6]. Besides $\gamma$ grain size, the carbides are most important in determining the LCF life of the material.

An example of carbides observed in the microstructure is shown in Fig. $3 b$ on an unetched aspolished surface. The carbide size and their distribution are primarily determined by the melt practice and the ingot size. The maximum carbide size, the frequency of carbide occurrence and the clustering tendency of the carbides are critical considerations in carbide fatigue initiation. In the IN718 material studied, the carbide sizes were evaluated in both billet and forged conditions, and two-parameter Weibull distributions of inverse carbide diameter for the both conditions are shown in Fig. 4. The largest carbides recorded were about $25 \mu \mathrm{m}$ in equivalent diameter and were found in the billet mid-radius location, however such large carbides occurred rarely. Following forging, the largest carbide measured about $20 \mu \mathrm{m}$ in equivalent diameter. The $\mathrm{MC}$
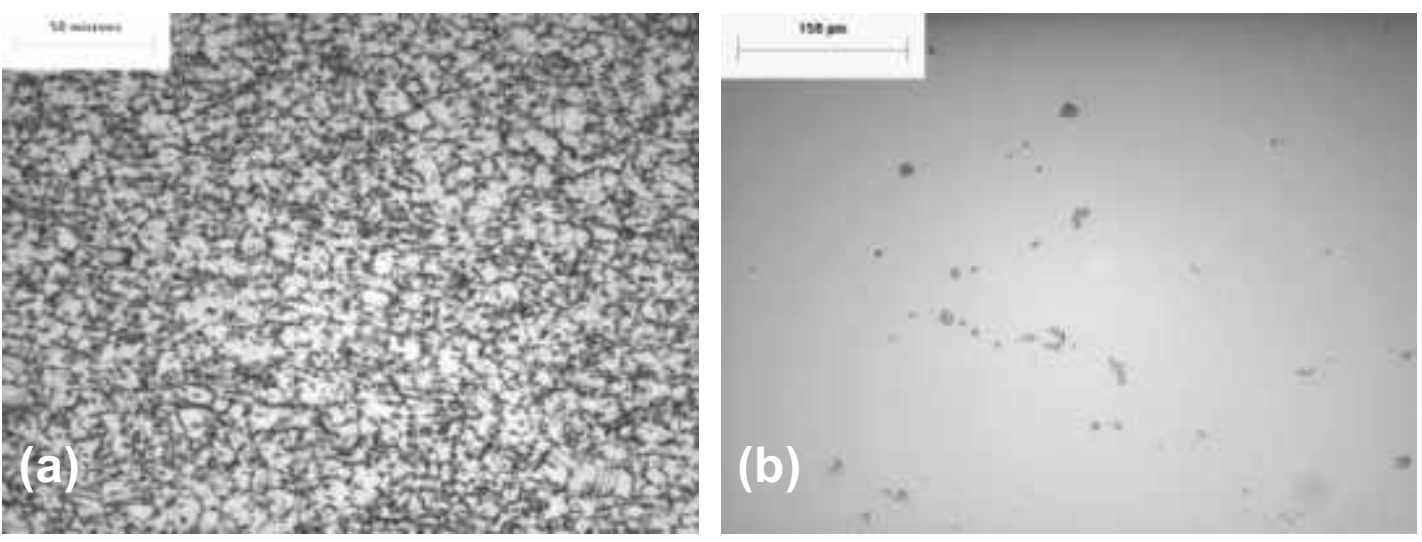

Figure 3. (a) Optical microscope image of fine gamma $(\gamma)$ grain structure after electroetching in a solution of $50 \% \mathrm{HCl}$ and $50 \%$ Methanol, and (b) Example of carbides on aspolished surface. 

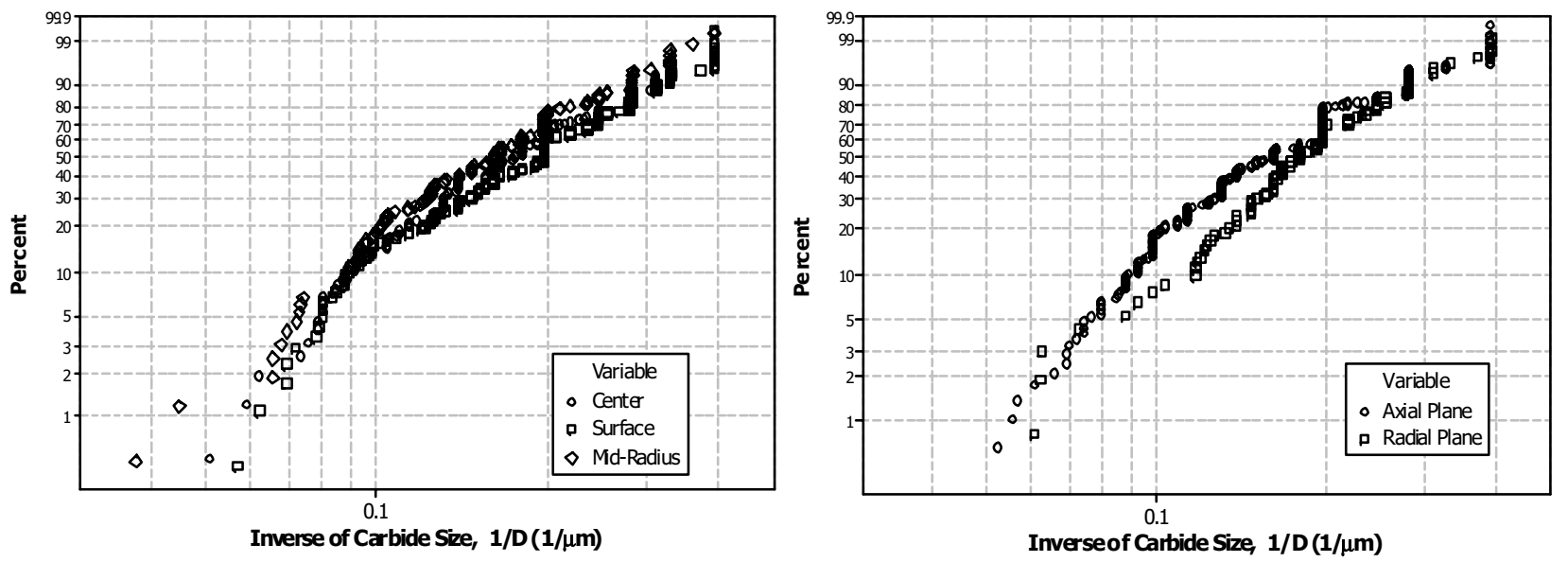

Figure 4. Carbide size distributions in Inconel 718 billet (left) and forging (right).

type carbides appeared to have the greatest influence on fatigue life when initiation occurred at carbides. The $\mathrm{MC}$ initiation sites were mostly $\mathrm{Nb}$ carbides with $\mathrm{Nb}(\mathrm{Ti}) \mathrm{C}$ representing only a small fraction of carbide-initiated failures.

\section{Notched Low Cycle Fatigue (LCF)}

Figure 5 shows the notched LCF results of the media-finished specimens tested at a notch-root concentrated stress of $1517 \mathrm{MPa}(220 \mathrm{ksi}$ ) and temperatures in the range $290 \mathrm{~K}$ to $880 \mathrm{~K}$ ( $70 \mathrm{~F}$ to 1125 F). The data in Fig. 5 are plotted using relative Y-axis scale for the cycles to failure. Three additional tests performed at a higher stress of $1655 \mathrm{MPa}(240 \mathrm{ksi})$ and temperature $560 \mathrm{~K}$ (550 F) are also included in Fig. 5. Either carbides or grains initiated the LCF failures in all specimens and these are distinguished in Fig. 5 by grey and white bars, respectively. The room temperature $(290 \mathrm{~K}) \mathrm{LCF}$ failures originated entirely from carbides at surface or subsurface locations, where a subsurface location was generally less than $20 \mu \mathrm{m}$ from the specimen surface. With increased temperature, in addition to carbides, grains contributed to fatigue initiation.

Examples of grain and carbide failures are shown in Fig. 6a and 6b, respectively. For the grain failures, the facet size at the fatigue initiation ranged from 15 to $30 \mu \mathrm{m}$ in equivalent diameter (approximate ASTM 7 to 9). These grains were coarser than the average grain size of $8 \mu \mathrm{m}$ (ASTM 11), and were previously characterized as occasional grains in the microstructure (typically $<2 \%$ of area fraction). The fatigue cracks initiating from carbides were found to be always $\mathrm{Nb}$ - or $\mathrm{Nb}$ /Ti-rich $\mathrm{MC}$ type carbides. An example of $\mathrm{Nb} / \mathrm{Ti}$-rich carbides at the failure origin is shown in the EDS mapping in Fig. 7. The carbide at the initiation site was fractured and was observed on both fracture surfaces. The typical size of the carbide at the initiation site ranged from 15 to $20 \mu \mathrm{m}$ and corresponded to the large carbides in the size distribution shown in Fig. 4. Thus, either the large carbides or the occasional coarser grains determined the LCF life in this material. 


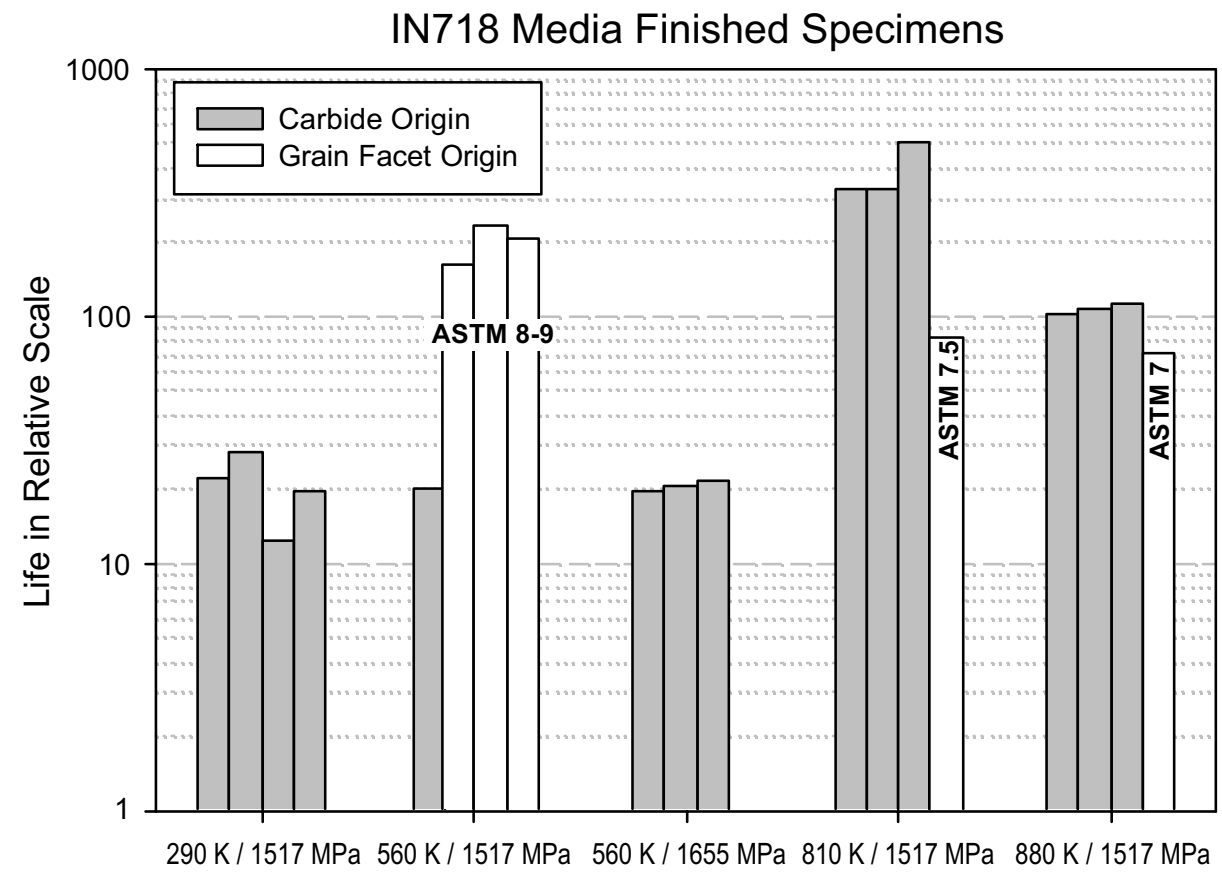

Figure 5. Notched LCF life of IN718 media-finished specimens for several test conditions. The cycles to failure are shown in a relative scale along the Y-axis, and grey and white bars are used to distinguish carbide and grain initiations of LCF failure, respectively.
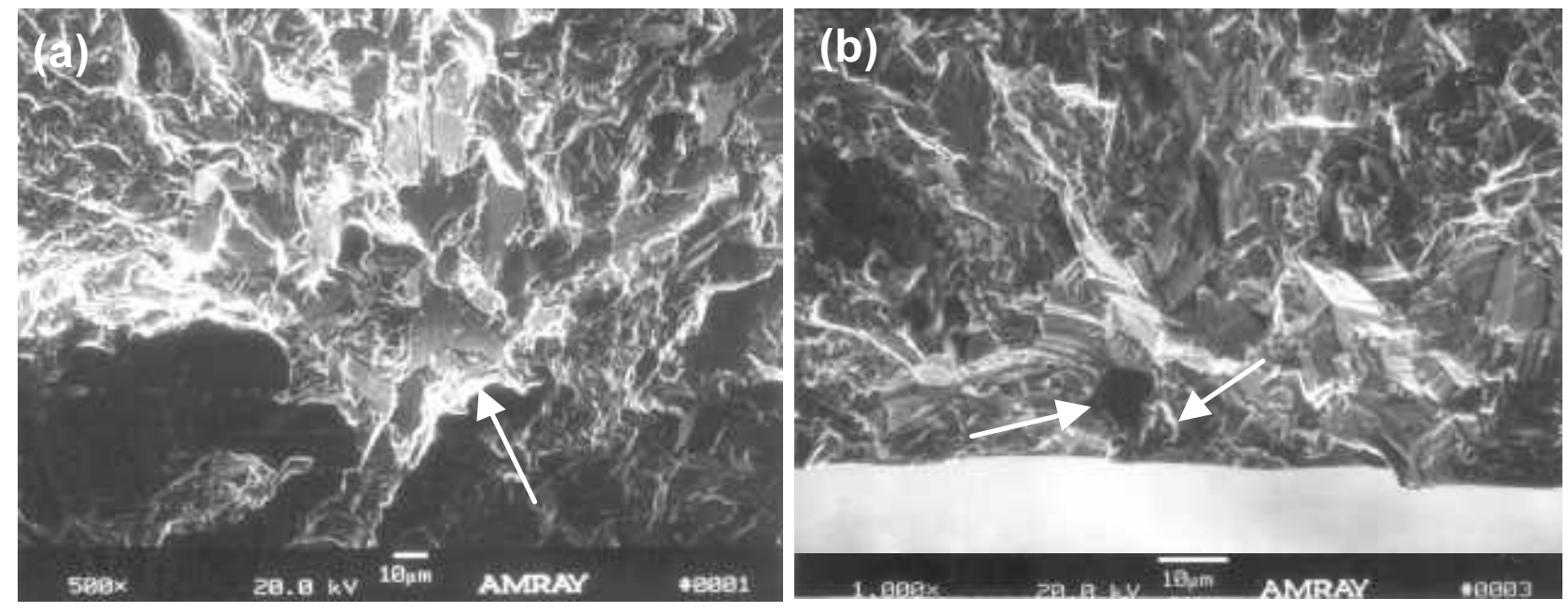

Figure 6. SEM images of LCF initiation sites of specimens tested at $560 \mathrm{~K} / 1517 \mathrm{MPa}$ showing grain (a) and carbide (b) origins at subsurface locations relative to the notch root surface (indicated by arrows).

For tests at room temperature $(290 \mathrm{~K})$ and $560 \mathrm{~K}$, the carbides were most life limiting (Fig. 5). The $560 \mathrm{~K}$ tests that included both carbide and grain initiations showed a significant reduction of LCF life from carbide initiation. At these temperatures, it appeared that the high stress in the vicinity of the notch-root was able to initiate cracks from carbides earlier than otherwise possible from grains. An SEM image of the notch surface at or near the notch root from a LCF specimen tested at $560 \mathrm{~K}$ and $1655 \mathrm{MP}$ that was interrupted in mid-life is shown in Fig. 8 to illustrate micro-cracks that are associated with carbides. These micro-cracks formed early in life, specially under condition of high stress amplitude, and resulted in overall reduction in the carbide initiated lives relative to those initiated by grains. 

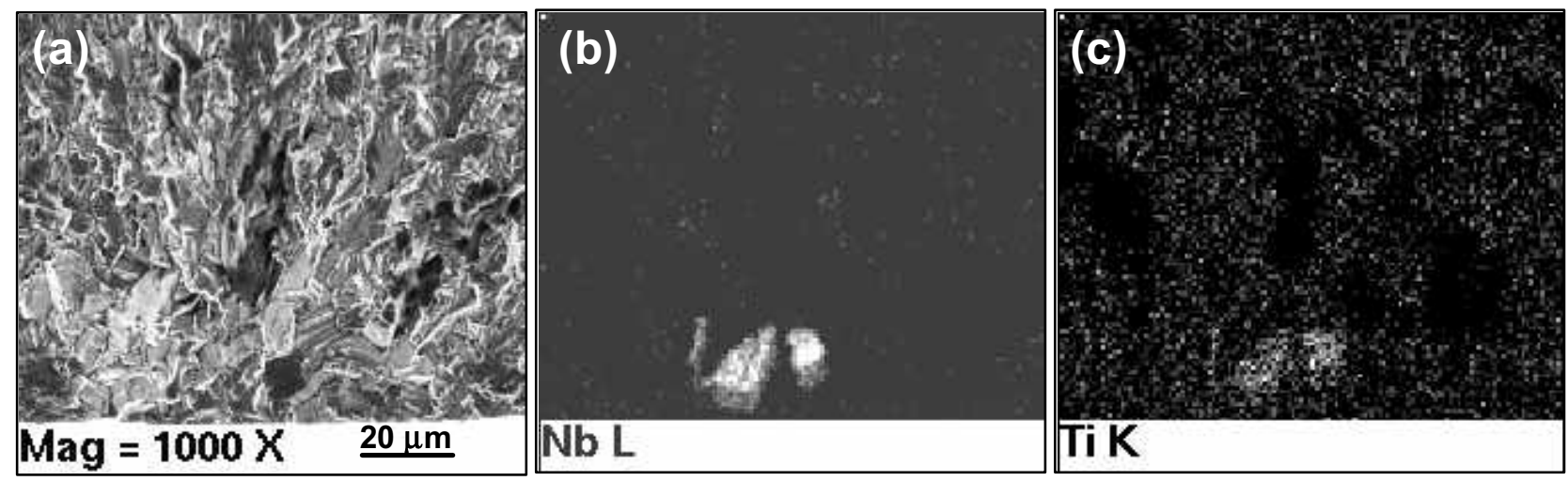

Figure 7. SEM secondary electron image (a), and EDS mapping of $\mathrm{Nb}$ (b) and $\mathrm{Ti}$ (c) of carbides at the LCF initiation site (specimen tested at $560 \mathrm{~K} / 1517 \mathrm{MPa}$ ).

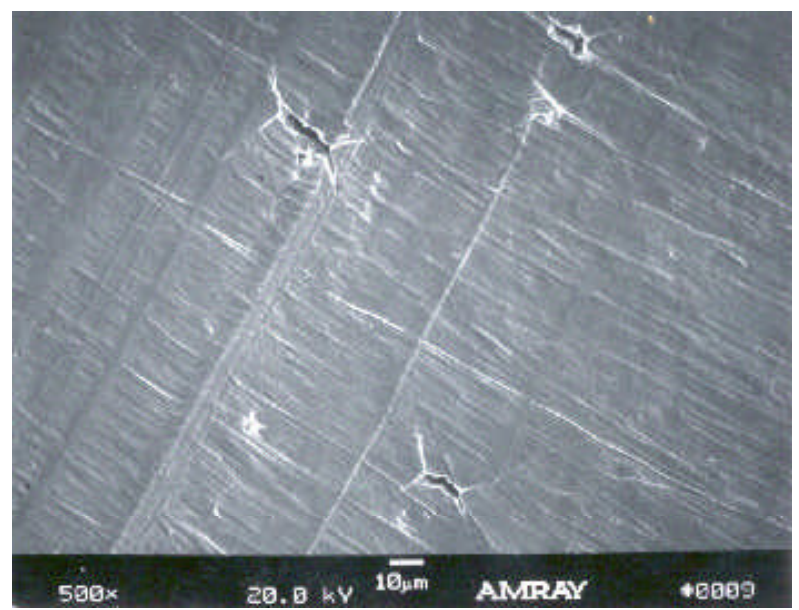

Figure 8. SEM image of the notch root of a LCF specimen that was interrupted in mid-life (tested at $560 \mathrm{~K}$ and $1655 \mathrm{MPa}$ ) to illustrate micro-cracks associated with carbides.

Cracking of carbides (or carbide cleavage) at low temperature and high stress leading to early crack initiation in smooth LCF tests was reported previously $[3,5]$. In the present study, however, the carbide cracking was further promoted by the notch root stress concentration. The carbide failures were life limiting only at lower temperatures. The data shown in Fig. 5 indicated that at higher temperatures $(810 \mathrm{~K}$ and $880 \mathrm{~K})$, carbide failures did not result in any reduction in life relative to grain failures, and the initiating carbides and the 'occasional' large grains were equally life limiting. In the higher temperature tests, there was evidence of cracked carbides in the vicinity of the notch root similar to those observed at lower temperatures, however the carbides were oxidized and the cracking was more limited to largest carbides. Examples of LCF initiation from carbide and secondary carbide cracking (near the primary carbide initiation site) in a specimen that was tested at $880 \mathrm{~K}$ and $1517 \mathrm{MPa}$ are shown in Fig. 9. The similarity of LCF life from carbide initiation (relative to 'occasional' large grain failures) at either 810 or $880 \mathrm{~K}$ suggests that at higher temperatures the crack initiation life for carbides is comparable to that of 'occasional' large grains. This behavior may be related to temperature dependent property change (such as hardness) of the carbides [7], and is further supported by the fact that the carbide initiated LCF life at higher temperatures increased tenfold relative to carbide initiated lower temperature LCF life. 

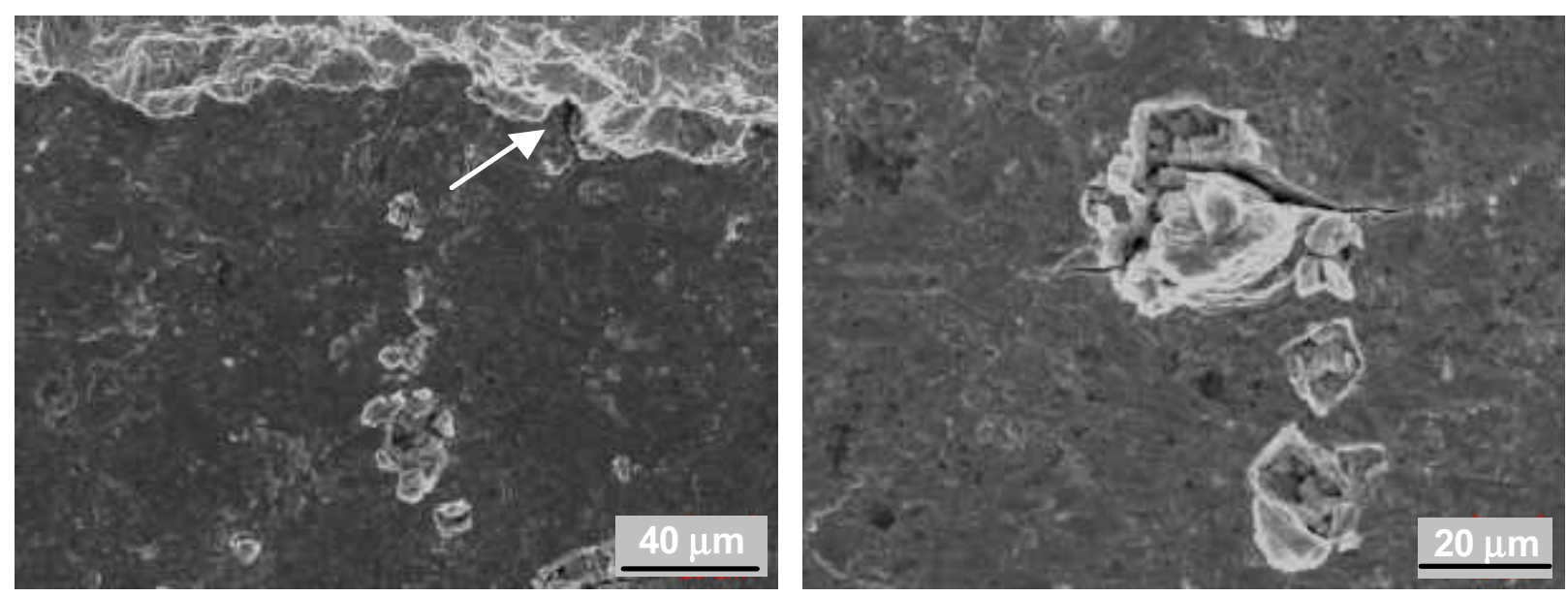

Figure 9. SEM image of the notch root of a specimen tested at $880 \mathrm{~K}$ and 1517 $\mathrm{MPa}$ showing carbide initiation (indicated by arrow) and secondary cracking of a large carbide adjacent to the fracture surface.

In order to further investigate the cracking of carbides, especially at lower temperature, limited LCF testing utilizing specimens in the as-machined condition was performed. It was shown in Fig. 1 that during machining of the notch, carbides at the machined surface of specimen appeared damaged by the cutter tip. It is likely that the cutter tip cracked the carbides, however no detailed evidence was established in the present study. Presuming the carbides are cracked prior to testing, the LCF test results from these specimens would essentially represent crack growth life from very small initial cracks in the size range of 15-20 $\mu \mathrm{m}$ (i.e. the cracked carbide size). Figure 10 shows the notch LCF results from as-machined specimens tested at $550 \mathrm{~K}$ and 1655 $\mathrm{MPa}$. It should be noted that for non-media finished specimens, failures always originated from carbides.

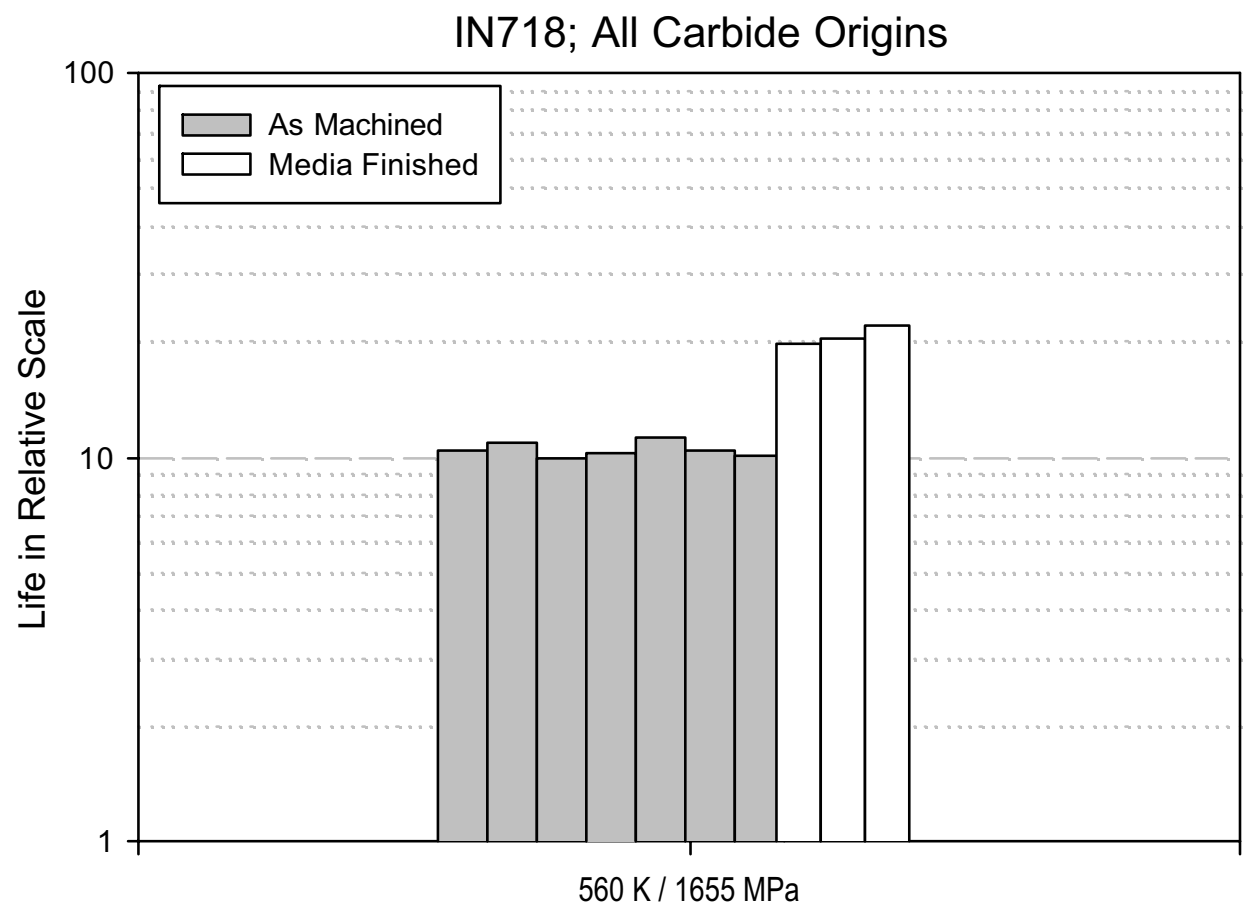

Figure 10. Notch LCF life (in relative scale) of IN718 as machined (grey bars) and media-finished (white bars) specimens tested at $560 \mathrm{~K}$ and concentrated stress of $1655 \mathrm{MPa}$. All specimens represent failure initiation from carbides. 


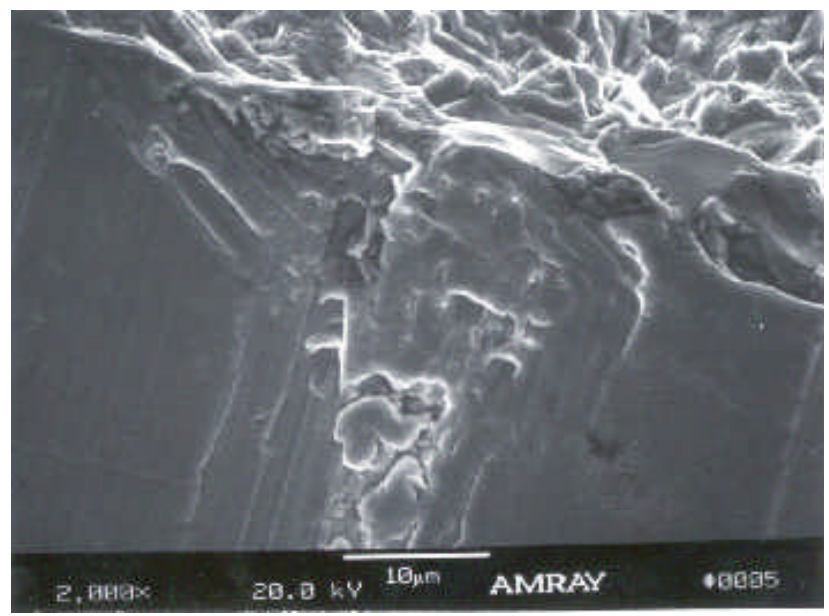

Figure 11. SEM image of LCF specimen tested in asmachined condition at $560 \mathrm{~K}$ and $1655 \mathrm{MPa}$ showing initiation from damaged carbide.

An example of failure initiation associated with surface carbides damaged by machining in the as- machined specimen is shown in Fig. 11. Figure 10 includes for comparison lives of carbideinitiated failures in media-finished specimens tested at the identical condition as the as-machined ones. It can be seen that the preexisting damaged (or possibly cracked) carbides resulted in a twofold reduction of LCF life in the as-machined specimens relative to the media-finished specimens.

The media-finish of the specimen notch changed not only the visual appearance of the surface by removal of material and damaged carbides (Fig. 2) but conceivably introduced compressive residual stress. The latter was not expected to play an important role in these tests due to high concentrated stresses at the notch root. It should be noted that no tests were done to determine the effects of as machined and media-finished surfaces on LCF life at higher temperatures, and therefore, LCF benefit from media-finished surface was not confirmed at higher temperatures.

\section{Conclusions}

(1) The role of carbides in the determination of notched LCF life of forged and heat-treated Inconel 718 was temperature dependent. At lower temperatures $(290 \mathrm{~K}$ and $560 \mathrm{~K})$, carbide initiation was dominant, and in situations of both carbide and grain initiated failures, carbide initiation occurred early leading to multiple micro-cracks in the vicinity of the highly stressed notch-root and an overall reduction in LCF life compared to grain initiated failures.

(2) With increased test temperature ( 810 and $880 \mathrm{~K}$ ), carbides still initiated a majority of the failures but the LCF life increased remarkably and became comparable to grain initiated failures. This behavior was attributed to longer crack initiation life of carbides at higher temperatures.

(3) The media-finish of the specimen notch had a beneficial effect on LCF life compared to the as machined surface. At lower temperatures $(290 \mathrm{~K}$ and $560 \mathrm{~K})$, 'damaged' carbides produced by cutter tip in the as-machined condition led to twofold or more reduction in LCF life. Mediafinish influence on LCF life at higher temperatures was not established in this study. 


\section{Acknowledgments}

The authors acknowledge support from Pratt \& Whitney, Connecticut in conducting this work, and Mr. Thomas E. Kenney of Pratt \& Whitney for various phases of metallographic and property evaluation.

\section{References}

[1] Merrick, H.F. Metall. Trans. 5A (1974) pp. 891-897.

[2] Fournier, D., and Pineau, A. Metall. Trans. 8A (1977) pp. 1095-1105.

[3] Spath, N., Zerrouki, V., Poubanne, P., Guedou, J.Y., in Superalloys 718, 625, 706 and Various Derivatives, (2001), pp. 173-183.

[4] Kobayashi, K., Yamaguchi, K., Hayakawa, M., and Kimura, M. Materials Letters, 59 (2005) pp. 383-386.

[5] Ono, Y., Yuri, T., Sumiyoshi, H., Takeuchi, E., Matsuoka, S., and Ogata, T. Materials Trans. 45 (2004) pp. 342-345.

[6] Brown, E.E., and Muzyka, D.R., 'Nickel-Iron Alloys", in Superalloys II, Ed. Sims, C.T., Stoloff, N.S., and Hagel, W.C., (1987) (John Wiley \& Sons) pp. 165-188.

[7] Aronssons, B., and Aschan, L.J., "Niobium in Cemented Carbide", in Niobium, Proc. Int. Symposium Niobium'81, Ed. Stuart, H., (1981) (Metall. Soc. AIME) pp. 637-651. 